\title{
Estimation of Seed Bank and Seed Viability of the Gulf of Saint Lawrence Aster, Symphyotrichum laurentianum, (Fernald) Nesom
}

\author{
JONI F. KEMP and Christian R. LACROIX ${ }^{1}$
}
Department of Biology, University of Prince Edward Island, 550 University Avenue, Charlottetown, Prince Edward Island C1A 4P3 Canada
${ }^{1}$ Author to whom correspondence should be addressed.

\begin{abstract}
Kemp, Joni F., and Christian R. Lacroix. 2004. Estimation of seed viability of the Gulf of Saint Lawrence Aster, Symphyotrichum laurentianum (Fernald) Nesom. Canadian Field-Naturalist 118(1): 105-110.
\end{abstract}

The Gulf of St. Lawrence Aster, Symphyotrichum laurentianum, is a member of the family Asteraceae and is listed as "threatened" by COSEWIC (Committee on the Status of Endangered Wildlife in Canada). This rare and vulnerable halophyte grows in only a few locations in New Brunswick, Prince Edward Island, and the Magdalen Islands, Quebec. As an annual, S. laurentianum relies exclusively on its seeds to survive to the next generation. The goal of this study was to estimate the quantity of viable $S$. laurentianum seeds in the persistent and transient seed banks at selected sites in Prince Edward Island. Overall, the number of seeds in the transient and persistent seed banks is low. The greatest concentration of seeds was found near the surface of the soil. In addition, only a small proportion of those seeds tested positive for viability based on Tetrazolium staining. Of the seeds in the persistent and transient seed banks combined, $53 \%$ were viable whereas only $2 \%$ of the seeds in the persistent seed bank were viable. Population surveys were also completed at the five known sites (both extinct and extant) in Prince Edward Island National Park. All sites showed signs of decline based on population estimates dating back to 1993. The Covehead Pond site showed the greatest decline: from 250-300 individuals in 1993 to only 10 individuals in 2002. The population at Dune Slack also showed a dramatic decrease from approximately 65000 in 1999, to 2200 individuals in 2002. Monitoring of this plant and the development of a management plan for the species are critical to its survival.

Key Words: Symphyotrichum laurentianum, Aster laurentianus, Gulf of St. Lawrence Aster, seed viability, Tetrazolium, transient and persistent seed banks, rare plant, COSEWIC, Prince Edward Island National Park.

The Gulf of St. Lawrence Aster, Symphyotrichum laurentianum (Fernald) Nesom, is a member of the family Asteraceae and is listed as "threatened" according to COSEWIC (Committee on the Status of Endangered Wildlife in Canada 2004*). It is an annual plant that relies exclusively on its seeds to survive until the next germination season, which makes this plant very vulnerable. S. laurentianum is a rare halophyte only found in a few areas in Prince Edward Island (PEI), New Brunswick (NB), and the Magdalen Islands in Quebec. It grows in salt marshes that are only flooded during spring and high tides. The St. Lawrence Aster has smooth, hairless, and fleshy linear-lanceolate to spatulate, generally sessile leaves (Figure 1). It can grow up to $30 \mathrm{~cm}$ tall and can bear 1 to over 700 flower heads (Houle and Haber 1990). Each flower head is subtended by leafy bracts and is composed exclusively of white to pink disk florets surrounded by a white pappus (Stewart 2000* and Figure 1). Seeds are enclosed in achene fruit walls when they are dispersed.

In 1990 fewer than 1000 plants were known to exist in PEI, NB and Quebec (Magdalen Islands) combined. However, further research and surveys have produced several new sites. While several sites in PEI and Quebec contain more than 1000 individuals each, the St. Lawrence Aster is still vulnerable to extinction (Gilbert et al. 1999*; Stewart and Lacroix 2001). Recent research conducted by Stewart $\left(2000^{*}\right)$ showed that population sizes could suddenly decline dramatically.
The extent of the persistent seed bank of a plant must be known in order to fully understand the germination ecology of the species (Baskin and Baskin 1998). In addition, the viability of a plant's seeds must also be maintained in order for the plant to be successful (Fenner 2000). A seed bank is a reserve of viable, ungerminated seeds in the soil. Seeds are considered viable if they have the ability/potential to germinate under favourable conditions (Baskin and Baskin 1998). There are two categories of seed banks: transient and persistent. A transient seed bank refers to a short-term storage of seeds, that is seeds that are viable for one year or one germination season. The seeds in the transient seed bank therefore germinate in the first year after dispersal. Any seeds that are dormant and survive to subsequent germination seasons are considered to be part of the persistent seed bank. The persistent seed bank contains seeds that remain viable in the soil for at least two germination seasons, making this a long-term reserve of seeds that are at least one year (or one germination season) old. A knowledge of both the extent of the seed banks and the germination potential of seeds of S. laurentianum constitutes crucial baseline data to develop a management plan for the species.

The specific goals of this study were: (1) to estimate the quantity of seeds in the seed bank (both transient and persistent) for S. laurentianum at each of the selected sites in PEI in order to evaluate the ability of the plant to maintain current populations, and (2) to test the 


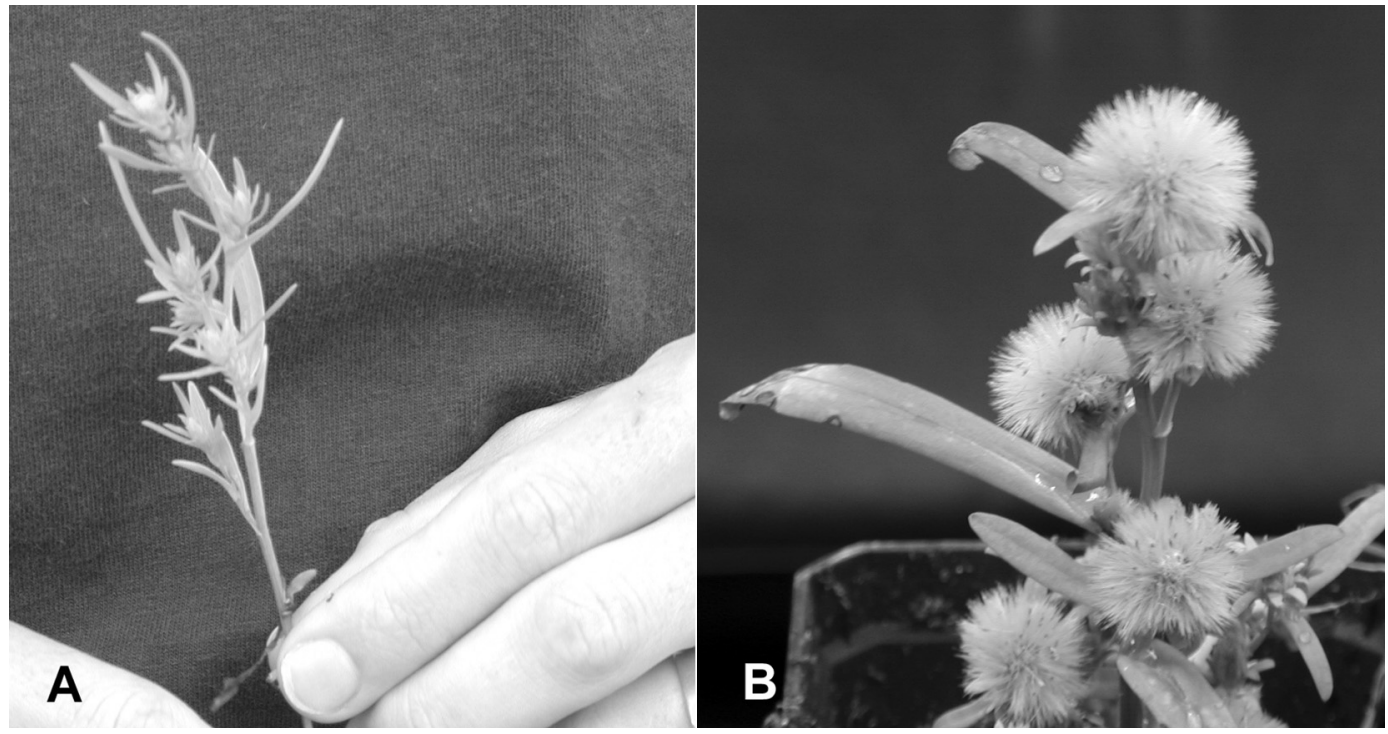

FIGURE 1. Representative photographs of Symphyotrichum laurentianum, pre-flowering (A) and post-flowering (B).

viability of seeds in the persistent seed bank and the transient seed bank.

\section{Materials and Methods \\ Population Surveys}

Five sites within the PEI National Park (Figure 2) were visited. Total population counts were made at the Covehead Pond and East Marsh A sites because of the small number of plants at these locations. The Western Wetland site was also surveyed to confirm that no asters were growing there. Population estimates were recorded for Dune Slack and East Marsh B sites because of the large population sizes. These estimates were accomplished by using a grid system. The general area where the plants were growing was subdivided into $0.5 \mathrm{~m}^{2}$ sections. A random number of sections was selected and all plants within these grids were counted. These counts along with the total area of the site were used to extrapolate the approximate number of plants found at each site.

\section{Collection of Soil Samples}

Soil cores were taken from five sites within PEI National Park (Figure 2), the only location in the province where the plant is found: Covehead Pond, Dune Slack, East Marsh A, East Marsh B and Western Wetland. Three transects were run at each site except Covehead Pond. Twenty coring points were flagged along three transects in Dune Slack. Due to sampling limitations imposed by Parks Canada, only ten coring points were flagged along three transects at East Marsh A and a further ten along the three transects at East Marsh B. Similarly, ten coring points were also flagged along the three transects for Western Wetland. Eleven coring points were flagged at Covehead Pond in a slightly different manner because of the physical nature of the site. Four transects were run from the water's edge of the pond to the high tide mark along the traditionally heavily populated side of the pond. Eight coring points were flagged evenly among these transects and the remaining three points were spaced evenly along the other side of the pond where the plants were also reported to grow.

Two sets of soil cores were taken from each site: one during late June/early July, and another during late August/early September. These dates were chosen to correspond to the type of seed bank that was sampled. The late June/early July samples were taken before the emergence of the 2002 season plants, to ensure that the transient as well as persistent seed banks were included. The late August/early September samples were taken after all the seeds that were going to germinate that season had germinated. Consequently, only the persistent seed bank was included in this specific sample date.

All the core samples were taken using an Oakfield "LS" 36" soil sampler with an effective coring length of $24 \mathrm{~cm}$ and an inner diameter of $1 \mathrm{inch}$. In order to study the vertical distribution of seeds in the soil, each soil core was divided equally into a top, middle, and bottom section. Each section of the core was labelled, placed into a separate bag, and put in a freezer set at $-4^{\circ} \mathrm{C}$ until processing which took place two weeks to three months later. All seeds found in the soil samples were tested for viability.

\section{Viability Testing}

Seeds were tested for viability using 2,3,5-triphenyl tetrazolium chloride (TTC) (Grabe 1970). The TTC test is based on a colour reaction: any seeds that are 


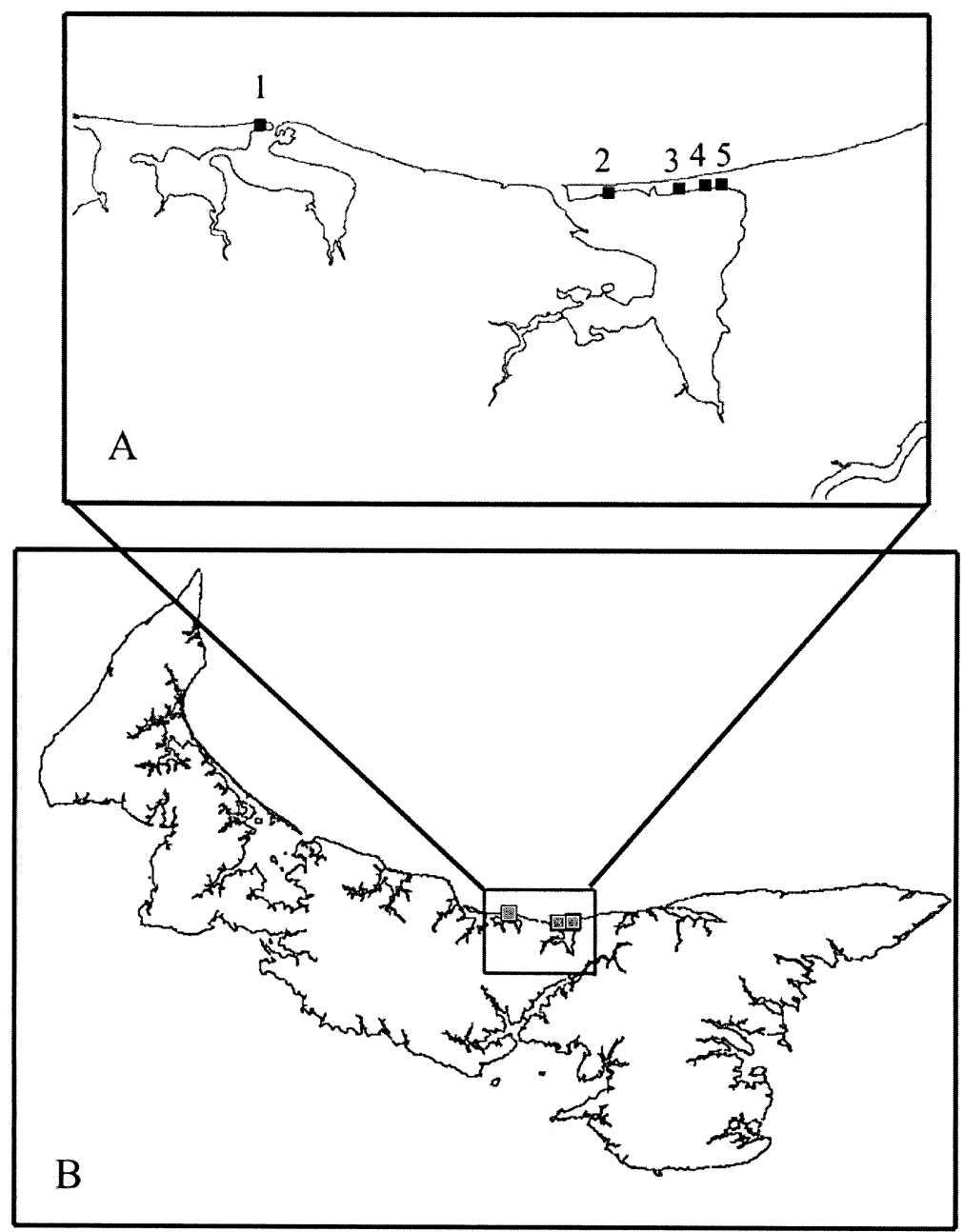

FIGURE 2. Map of all Prince Edward Island sites used in this study. Study sites are depicted as squares on both maps. All five sites shown in (A) are located in the national park: 1. Covehead Pond, 2. Western Wetland, 3. Dune Slack, 4. East Marsh B, and 5. East Marsh A. (B) Location of sites on Prince Edward Island with black square highlighting the specific area shown in (A).

viable will stain pink/red. Complete achenes (containing seeds) were placed on a piece of filter paper in a petrie dish, and left overnight to soak in distilled water. The next day, when the seeds were fully imbibed with water, they were dissected out of the achene fruit wall and seed coat. After removal of the seed coat, the embryos were placed in a $1 \%$ TTC solution for two hours at $35^{\circ} \mathrm{C}$, as prescribed for dicotyledonous seeds. The embryos were then evaluated for viability according to the scheme developed in Grabe (1970). As a general rule, the radicle, shoot tip and cotyledons must stain pink/red in order for the seed to be considered viable.

\section{Statistical Analysis}

The viability of seeds in the soil was compared graphically for vertical distribution and sampling dates. Statistical analysis was not possible on these data because there was no replication. Due to the vulnerable status of the plant, sampling was limited by restrictions on collecting imposed by Parks Canada. The vertical distribution of seeds and fruit walls within the soil was compared using Kruskal-Wallis tests (non parametric equivalent of ANOVA). All data from the five sampling sites on PEI were pooled for analysis. 


\section{Results}

Population Sizes

Population sizes for all known PEI sites are shown in Table 1. All populations experienced a decrease in numbers, the most noticeable of these being the population at the Dune Slack site with more than 95\% decline. The smallest population at the Covehead Pond site also experienced a decrease from 243 individuals in 1999 to only 10 individuals in 2002.

\section{Seed Banks}

A total of 122 cores were taken from PEI sites. Of these, 32 contained at least one seed. There were significantly more seeds in the top portion of those cores than in any other portion of the soil samples (Figure 3; Kruskal-Wallis test; $P<0.05, \mathrm{n}=45$ for each portion). The non-random distribution of the seeds, as evidenced by the highly variable number of seeds found in the core samples, is also highlighted in Figure 3. This may be related to where the plants clustered the year before, a factor we were not able to determine prior to establishing coring sites.

\section{Seed Viability}

There was a noticeable decline in the percentage of viable seeds among the top, middle, and bottom sections of the soil cores taken on PEI. We found that $28.4 \%$ of the seeds in the top section of the cores were viable compared to $20 \%$ of the seeds in the middle section of the cores. None of the seeds in the bottom section of the cores were viable.

There was a marked decline in the percentage of viable seeds between the late June/early July sample and the late August/early September sample (Figure 4). The percentage of viable seeds in the persistent seed bank $(2 \%)$ is practically non-existent when compared to the viability of the seeds in the persistent and transient seed banks combined (53\%). This means that the majority of viable seeds germinate within one year of being produced.

\section{Discussion \\ Population Sizes}

Symphyotrichum laurentianum populations on PEI continue to show dramatic fluctuations and it can be very difficult for an annual plant to rebound from these declines in population size. Although the Dune Slack site was considered one of the two largest populations on PEI; its rate of decline, if maintained, will bring the population down to a size comparable to the smallest populations. A comparatively small population at Covehead Pond has been relatively stable at 150 to 300 individuals for the past ten years but the last population count found only ten individuals which, coupled with the low viability of seeds in the seed banks, indicates that this site is on the verge of extinction if preventive measures are not taken.

The Island Nature Trust, a local conservation organization, conducted a survey of suitable areas on PEI in 2002 to locate new populations of S. laurentianum. Several prime candidate habitats were located but unfortunately no asters were found at those sites (MacQuarrie, personal communication).

\section{Seed Banks}

There appears to be a lack of mixing of the soil in the salt marshes which causes a clustering of seeds in the top sections of the soil. This trend is obvious in the vertical distribution of seeds shown in Figure 3. Seeds that remain trapped in the upper layer of the soil are more likely to get exposed to the elements thereby potentially affecting the viability of the embryo.

One of the most meaningful results from this study is the fact that the viability of seeds in the persistent seed bank is practically non-existent. This can be devastating for an annual plant such as $S$. laurentianum. Without the long-term storage of viable seeds, this plant is vulnerable to short term changes in its habitat, both natural and anthropogenic.

TABLE 1. Comparison of population sizes for Symphyotrichum laurentianum on Prince Edward Island.

\begin{tabular}{|c|c|c|c|c|}
\hline Population & GPS Location & 1992 & 1999 & 2002 \\
\hline Covehead Pond & $\begin{array}{l}46^{\circ} 25^{\prime} 49.39^{\prime \prime} \mathrm{N} \\
63^{\circ} 09^{\prime} 07.98^{\prime \prime} \mathrm{W}\end{array}$ & 168 & 243 & 10 \\
\hline Western Wetland & $\begin{array}{l}46^{\circ} 24^{\prime} 47.88^{\prime \prime} \mathrm{N} \\
63^{\circ} 01^{\prime} 16.89^{\prime \prime} \mathrm{W}\end{array}$ & 425 & 0 & 0 \\
\hline Dune Slack & $\begin{array}{l}46^{\circ} 24^{\prime} 51.49^{\prime \prime} \mathrm{N} \\
62^{\circ} 59^{\prime} 41.98^{\prime \prime} \mathrm{W}\end{array}$ & $15000-20000^{*}$ & $65250^{*}$ & $2200^{*}$ \\
\hline East Marsh A & $\begin{array}{l}46^{\circ} 24^{\prime} 55.97^{\prime \prime} \mathrm{N} \\
62^{\circ} 58^{\prime} 43.89^{\prime \prime} \mathrm{W}\end{array}$ & $50000-60000^{*}$ & $25000-60000 *$ & 133 \\
\hline East Marsh B & $\begin{array}{l}46^{\circ} 24^{\prime} 55.27^{\prime \prime} \mathrm{N} \\
62^{\circ} 59^{\prime} 06.11^{\prime \prime} \mathrm{W}\end{array}$ & $\begin{array}{l}\text { (Sites A and } \\
\text { B combined) }\end{array}$ & $\begin{array}{l}\text { (Sites A and } \\
\text { B combined) }\end{array}$ & $44100^{*}$ \\
\hline
\end{tabular}

\footnotetext{
* estimate
} 


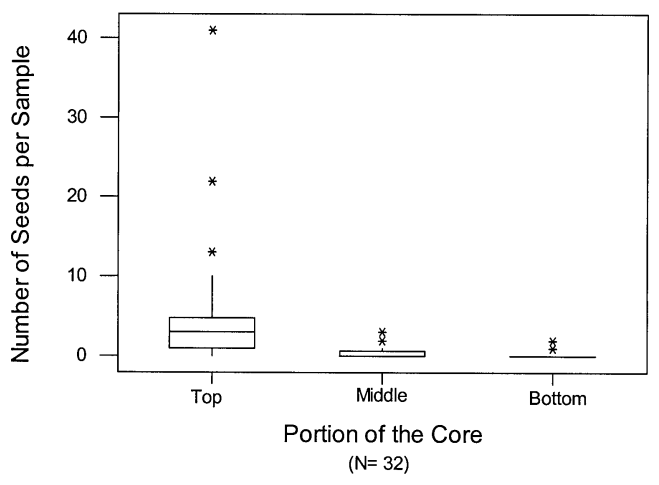

FIGURE 3. Box plots showing median (centre line) and $25^{\text {th }}$ and $75^{\text {th }}$ percentile for numbers of seeds found in cores from all Prince Edward Island soil samples that contained seeds. Outliers $(*)$ are included to show the non-random distribution of the seeds.

During the summer of 2002, the Dune Slack site was heavily flooded during a storm. This caused the site, and consequently the maturing aster plants, to be smothered in eel grass. Since the Dune Slack population had already experienced a dramatic decrease in size between 1999 and 2002, the necessary number of mature viable seeds needed to survive this natural short-term event may not be available.

Covehead Pond is an example of a site that is very likely to become extinct due to anthropogenic causes. This site is isolated from Covehead Bay by a road. The culvert that is presently in place did not allow proper drainage from the pond during the summer of 2002 and caused this site to be flooded. The ten plants that were

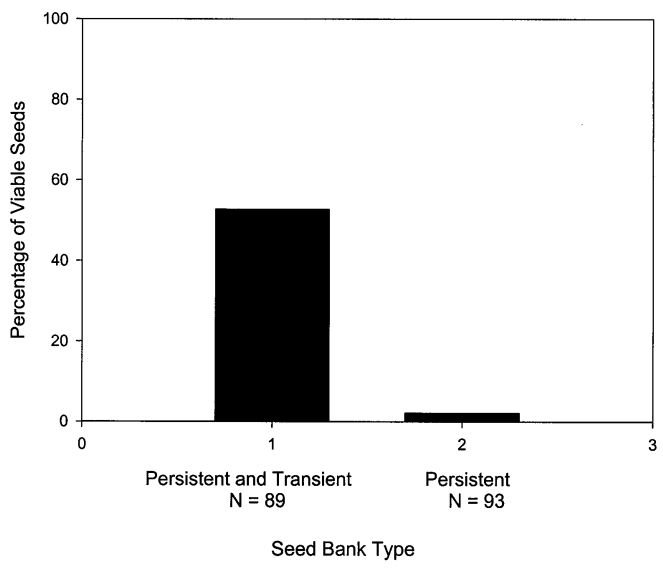

FIGURE 4. The percentage of viable seeds in the seed banks on Prince Edward Island. Persistent and transient seed banks $=$ all late June/early July samples on Prince Edward Island. Persistent seed bank = all late August/ early September samples on Prince Edward Island. seen at this site in 2002 were flooded by water and also smothered by eel grass. This occurred at a crucial time during seed maturation. Only one plant was found at the Covehead site in 2003.

\section{Status of the Species}

In 2003, there were 441 Canadian species at risk, and 140 of these were plants (Committee on the Status of Endangered Wildlife in Canada 2004*). Until recently, there has been very little in terms of Federal legislation in place to protect these species. The Species at Risk Act (SARA) which came into effect in 2002 will hopefully facilitate this process especially with regard to developing a plan for the recovery of every extirpated, endangered, or threatened species.

The results of this study show a disturbing trend: the estimated number of seeds in the seed banks is low, the viability of the seeds in those seed banks is also low (especially in the persistent seed bank), and the populations are declining. The Gulf of St. Lawrence Aster is currently under review and it is important that all available information on the biology of the species be considered (especially information pertaining to seed banks). The status of this plant has recently been updated to "threatened" which is defined as "a species that is likely to become endangered if nothing is done to reverse the factors leading to its extirpation or extinction" (Committee on the Status of Endangered Wildlife in Canada 2004*). This new designation confirms the urgent need to design a management plan for S. laurentianum to ensure that it does not become extinct. Although harsh weather patterns leading to strong winds and flooding cannot be prevented (i.e., extreme flooding of the Dune Slack site during summer of 2002), alternate measures such as transplanting ex situ plants into affected sites should be considered. Preliminary results show that seedlings of $S$. laurentianum can be grown from seed and transplanted from culture medium to soil with a relatively high success rate (Stewart 2000*). However, a population decline and loss of suitable habitat due to anthropogenic activities can be prevented and further steps, such as ensuring proper drainage at a site such as Covehead Pond, should be taken.

\section{Acknowledgments}

This research was partially funded by an NSERC (National Sciences and Engineering Research Council) operating grant to C. Lacroix. We would like to thank Parks Canada for allowing us access to the sites to collect samples. Thank you to Kate MacQuarrie for her comments on this manuscript.

Documents Cited (marked $*$ in text)

Committee on the Status of Endangered Wildlife in Canada. 2004. COSEWIC assessment and update status report on the Gulf of St. Lawrence Aster, Symphyotrichum laurentianus in Canada. Ottawa. 39 pages. Retrieved May 2004, from http://www.cosewic.gc.ca 
Gilbert, H., J. Labrecque, and J. Gagnon. 1999. La situation de l'aster du Saint-Laurent (Aster laurentianus, syn. : Symphyotrichum laurentianum) au Canada. Ministère de l'Environnement Direction de la conservation et du patrimoine écologique, Québec.

Stewart, S. E. 2000. Micropropagation of Aster laurentianus. Unpublished honours thesis, University of Prince Edward Island, Charlottetown, Canada.

\section{Literature Cited}

Baskin, C. C., and J. M. Baskin. 1998. Seeds: Ecology, biogeography, and evolution of dormancy and germination. Academic Press, San Diego.

Fenner, M. 2000. Seeds: The ecology of regeneration in plant communities. CABI Publishing, New York.
Grabe, D. F., Editor. 1970. Tetrazolium testing handbook for agricultural seeds: contribution Number 29 to the handbook on seed testing. Tetrazolium Testing Committee of the Association of Official Seed Analysts.

Houle, F., and E. Haber. 1990. Status of the Gulf of St. Lawrence Aster, Aster laurentianus (Asteraceae), in Canada. Canadian Field-Naturalist 104: 455-459.

Stewart, S. E., and C. R. Lacroix. 2001. Germination potential, updated population surveys and floral, seed and seedling morphology of Symphyotrichum laurentianum, the Gulf of St. Lawrence Aster, in the Prince Edward Island National Park. Canadian Field-Naturalist 115: 287-295.

Received 2 June 2003

Accepted 3 June 2004 